\title{
Antitumor activity and biodistribution of cisplatin nanocapsules in nude mice bearing human ovarian carcinoma xenografts
}

\author{
Rutger W.H.M. Staffhorst ${ }^{a}$, Kasper van der Born ${ }^{b}$, Caroline A.M. Erkelens ${ }^{b}$, \\ Irene H.L. Hamelers ${ }^{a}$, Godefridus J. Peters ${ }^{b}$, Epie Boven ${ }^{b}$ and \\ Anton I.P.M. de Kroon ${ }^{\mathrm{a}}$
}

\begin{abstract}
Cisplatin nanocapsules represent a novel lipid formulation of the anticancer drug cis-diamminedichloridoplatinum(II) (cisplatin), characterized by an unprecedented cisplatin-tolipid molar ratio, and exhibiting strongly increased in-vitro cytotoxicity compared with the free drug. In this study, antitumor efficacy and biodistribution of PEGylated cisplatin nanocapsules were compared with those of the free drug in a mouse tumor model. Nude mice bearing human ovarian carcinoma OVCAR-3 xenografts were treated twice with a 1-week interval by intravenous administration of cisplatin nanocapsules or cisplatin in solution, and the growth inhibitory effects were determined by measurement of tumor volumes. At a dose of $3 \mathrm{mg}$ cisplatin $/ \mathrm{kg}$, corresponding to the maximum tolerated dose of cisplatin nanocapsules, cisplatin nanocapsules and cisplatin in solution exhibited similar therapeutic effectiveness, reducing tumor growth by $90 \%$ at day 20 after first injection. The platinum biodistribution was assayed by analyzing plasma and tissues for total platinum content by nonflame atomic absorption spectroscopy.

Plasma and tumor concentrations of platinum were similar for both formulations. During the first hour after injection of cisplatin nanocapsules, the platinum content of the kidney was $40 \%$ less than that after administering the free drug.
\end{abstract}

Platinum from nanocapsules showed rapid and 4.5-fold higher accumulation in the liver compared with free cisplatin, and, at a slower rate, accumulation to a high concentration in the spleen. We conclude that the formulation of cisplatin nanocapsules inhibits the growth of OVCAR-3 xenografts in nude mice, albeit to a similar extent as free cisplatin. The results suggest that the antitumor efficacy of the nanocapsules could be improved by preventing rapid clearance from circulation. Anti-Cancer Drugs 19:721-727 (c) 2008 Wolters Kluwer Health | Lippincott Williams \& Wilkins.

Anti-Cancer Drugs 2008, 19:721-727

Keywords: biodistribution, cisplatin, drug delivery, lipid formulation, nanocapsules, ovarian carcinoma xenograft

aDepartment of Biochemistry of Membranes, Bijvoet Institute and Institute of Biomembranes, Utrecht University, Utrecht and ${ }^{\text {b Department of Medical }}$ Oncology, VU University Medical Center, Amsterdam, The Netherlands

Correspondence to Anton de Kroon, Membrane Enzymology, Utrecht University, Padualaan 8, $3584 \mathrm{CH}$ Utrecht, The Netherlands

Tel: + 3130 2533424; fax: +3130 2522478; e-mail: a.i.p.m.dekroon@uu.nl

Received 8 February 2008 Revised form accepted 10 April 2008

nanosize particle formulations of cisplatin have been developed, including lipid-based formulations, the most recent being SPI-077 [7] and lipoplatin [8]. In SPI-077 cisplatin is enclosed in sterically stabilized, PEGylated (stealth) liposomes consisting of hydrogenated soy phosphatidylcholine (PC), cholesterol, and polyethylene-glycol (PEG) derivatized distearoylphosphatidylethanolamine. In preclinical studies, SPI-077 exhibited a prolonged circulation time, increased antitumor efficacy and reduced toxicity compared with free cisplatin [7,9]. In phase I-II clinical trials, however, essentially no antitumor efficacy of SPI-077 was found [10,11]. Lipoplatin did exhibit antitumor efficacy in phase I-II trials with reduced side effects compared with the free drug, and has entered phase III trials [12]. Recently, a liposomal formulation of cisplatin was used to increase the local penetration of cisplatin after inhalation in patients with carcinoma of the lung [13].
To reduce the toxic side effects, to overcome resistance, and to increase the therapeutic index of cisplatin, various 
A disadvantage of liposomal formulations of cisplatin is the limited bioavailability of the drug in the tumor [14-16]. This is attributed to the low solubility of cisplatin in water, giving rise to liposomal formulations with relatively low drug-to-lipid molar ratios, and the slow kinetics of release. Recently, a method was reported for encapsulating cisplatin in a lipid formulation with an extremely high encapsulation efficiency [17]. The method consists of repeatedly freezing and thawing a concentrated aqueous solution of cisplatin in the presence of equimolar amounts of PC and phosphatidylserine (PS), and produces cisplatin nanocapsules, beanshaped nanoprecipitates of cisplatin coated with a lipid bilayer. The nanocapsules represent a novel lipid formulation of cisplatin characterized by an unprecedented cisplatin-to-lipid molar ratio and by a strongly improved cytotoxicity against tumor cells in vitro as compared with the free drug. The formation of the nanocapsules critically depends on the presence of negatively charged phospholipids and positively charged aqua-species of cisplatin [17,18]. Cisplatin nanocapsules have a negative $\varsigma$ potential $(-44 \mathrm{mV})$ and a heterogeneous size distribution as determined by dynamic light scattering [17], with $75 \%$ of the population having a width around $50 \mathrm{~nm}$ and a length between 50 and $250 \mathrm{~nm}$ as determined by electron microscopy [19]. Analysis of the contents of the nanocapsules by magic-angle spinning ${ }^{15} \mathrm{~N}$ nuclear magnetic resonance revealed that $90 \%$ of cisplatin in the solid core of cisplatin nanocapsules is present as the dichlorido species [18].

This study addressed the antitumor efficacy of cisplatin nanocapsules in vivo, in nude mice bearing human ovarian carcinoma xenografts. In addition, the biodistribution of cisplatin from nanocapsules was studied and compared with that of the free drug. To improve the stability of the cisplatin PC/PS nanocapsules in mouse serum, nanocapsules were prepared in which cholesterol and PEGmodified lipids were included in the bilayer coat [20]. Cholesterol is known to reduce membrane permeability, whereas the PEG moieties oriented toward the aqueous solution confer steric stabilization, and should prevent opsonization of nanocapsules and uptake by the reticuloendothelial system [21]. PEGylation was shown to prolong the lifetime of cisplatin nanocapsules in serum to almost $1 \mathrm{~h}$ without adverse effects on cisplatin-to-lipid ratio, size and size distribution, and in-vitro cytotoxicity [20].

\section{Methods}

\section{Preparation of cisplatin nanocapsules}

Cisplatin (Sigma, St Louis, Missouri, USA) was dissolved in water at a concentration of $5 \mathrm{mmol} / \mathrm{l}$ and incubated overnight in the dark at $37^{\circ} \mathrm{C}$ to ensure full equilibration. Cisplatin nanocapsules were prepared by hydrating dry lipid films $(1.2 \mu \mathrm{mol})$ consisting of 1,2-dioleoyl- sn-glycero-3-phosphocholine, 1,2-dioleoyl-sn-glycero-3phosphoserine, cholesterol (Avanti Polar Lipids Inc., Birmingham, Alabama, USA), and 1,2-distearoyl-sn-glycero-3-phosphoethanolamine- $N$-[poly (ethylene glycol)2000] (DSPE-PEG2000; Sigma), in a molar ratio of $27: 27$ : $40: 6$, with $1.2 \mathrm{ml} 5 \mathrm{mmol} / \mathrm{l}$ cisplatin in water at $37^{\circ} \mathrm{C}$ for $30 \mathrm{~min}$. The resulting suspension was subjected to 10 freeze thaw cycles as described [19]. Cisplatin nanocapsules were collected by centrifugation at low speed (4 min at $2100 \mathrm{rpm})$ in an Eppendorf centrifuge (Eppendorf AG, Hamburg, Germany), washed by resuspension in $1 \mathrm{ml}$ of water and centrifuged as above, and stored at $4^{\circ} \mathrm{C}$ until use. Platinum contents of cisplatin nanocapsule preparations were quantified by nonflame atomic absorption spectroscopy on a SpectrAA-400 Zeeman spectrometer (Varian, Palo Alto, California, USA), using a modifier solution of $0.5 \%$ Triton X-100 in water, and $\mathrm{K}_{2} \mathrm{PtCl}_{6}$ as a standard [22]. Batches of cisplatin nanocapsules were characterized for platinum and phospholipid contents, yielding the typical platinum/phosphorus molar ratio of $11 \pm 2$ [20].

\section{Animals}

Female nude mice (Hsd: athymic nude-nu) were purchased at the age of 6 weeks (Harlan, Horst, The Netherlands). The animals were maintained in cages with paper filter covers under controlled atmospheric conditions. Cages, covers, bedding, food, and water were changed and sterilized weekly. Animals were handled in a sterile manner in a laminar down-flow hood. Ethics approval was obtained from the ethics committee for animal experiments of the VU University (Amsterdam, The Netherlands) for transplantation of human tumor tissue and for treatment experiments in nude mice. This committee strictly adheres to the standards required by the United Kingdom Coordinating Committee on Cancer Research for the welfare of animals in neoplasia [23].

\section{Antitumor activity}

OVCAR-3 ovarian carcinoma xenografts were generated as described [24], and grown subcutaneously in nude mice. For transplantation, tumor fragments with a diameter of 2-3 $\mathrm{mm}$ were implanted into both flanks of 8 -week-old to 10 -week-old nude mice. Upon growth, tumors were measured twice a week in three dimensions with a slide calliper. Tumor volumes (in $\mathrm{mm}^{3}$ ) were calculated by the equation $a b c / 2$, with $a, b, c$ representing tumor length, width, and thickness, respectively. Mice were weighed at the time of tumor measurements.

Treatment was started on day 0 in groups of five mice with a mean tumor volume of approximately $100 \mathrm{~mm}^{3}$ in each group. Cisplatin in aqueous solution (Bristol-Myers Squibb, Woerden, The Netherlands) and cisplatin nanocapsules were administered intravenously (i.v.) weekly $\times 2$ at doses up to the maximum tolerated dose (MTD). At the MTD, the mice showed a reversible 
weight loss up to $15 \%$ of the initial weight within 2 weeks after the start of treatment.

In the evaluation of response, tumors that had not reached $20 \mathrm{~mm}^{3}$ at the start of treatment were considered not evaluable. The increase in tumor volume from the start of treatment $\left(V_{0}\right)$ to the value at any given time $\left(V_{\mathrm{t}}\right)$ was calculated for each tumor, and expressed as the relative tumor volume $\left(V_{\mathrm{t}} / V_{0}\right)$ on the day of measurement. The mean of these values was used to calculate the efficacy in percentage as the ratio between treated $(\mathrm{T})$ and control $(\mathrm{C})$ tumors $(\mathrm{T} / \mathrm{C} \times 100 \%)$.

\section{Biodistribution}

Randomized groups of three nude mice bearing OVCAR3 xenografts with an average tumor volume of 250 $300 \mathrm{~mm}^{3}$ received a single dose of $4 \mathrm{mg} / \mathrm{kg}$ of either cisplatin or cisplatin nanocapsules at time zero. At the time-points indicated, the mice were injected with nembutal $(150 \mathrm{mg} / \mathrm{kg})$, bled from the axillary vein, and sacrificed by cervical dislocation. Subsequently, liver, kidneys, lungs, spleen, and tumors were collected. Blood was centrifuged and plasma was stored at $-20^{\circ} \mathrm{C}$ until analysis. Tissues were immediately frozen in liquid nitrogen and stored at $-80^{\circ} \mathrm{C}$ until analysis.

For platinum analysis, $100-\mathrm{mg}$ tissue samples were dissolved in $1 \mathrm{ml}$ concentrated nitric acid overnight at $50^{\circ} \mathrm{C}$. After addition of $20 \mu \mathrm{l} 0.1 \mathrm{~g} / \mathrm{ml} \mathrm{NaCl}$, the solvent was evaporated at $100^{\circ} \mathrm{C}$ under a stream of $\mathrm{N}_{2}$. Residues were dissolved in $1 \mathrm{ml} 0.2 \mathrm{~mol} / \mathrm{l} \mathrm{HCl}, 0.15 \mathrm{~mol} / \mathrm{l} \mathrm{NaCl}$ by sonication for $10 \mathrm{~min}$, and incubation for $1 \mathrm{~h}$ at $50^{\circ} \mathrm{C}$. Plasma samples were diluted $1: 1$ with $0.9 \% \mathrm{NaCl}$ in $0.4 \mathrm{~N} \mathrm{HCl}$. After centrifugation for $2 \mathrm{~min}$ at $4000 \mathrm{rpm}$ (Eppendorf centrifuge), $1 \mathrm{ml}$ of $0.1 \%(\mathrm{v} / \mathrm{v})$ Triton X-100, $0.1 \%(\mathrm{v} / \mathrm{v})$ antifoam B was added to the supernatants. Total platinum concentration was analyzed by flameless atomic absorption spectrometry using a spectra AA-300 Zeeman AAS (Varian) as described earlier [13,25]. Standards consisting of blank plasma and tissue spiked with platinum were treated in the same way. In these samples, the recovery over the whole concentration range was $104 \pm 11 \%$. We tested the recovery in tissues using liver, because it was easily available in a large amount.
The accuracy and precision of the assays for these analyses were $98.4 \pm 3.5$ and $2.94 \pm 3.4 \%$, respectively. Platinum contents were expressed as nmol per gram of wet weight for tissues, and as $\mu \mathrm{mol} / \mathrm{l}$ for plasma. The assay was linear over a range of $0.1-10 \mu \mathrm{mol} / \mathrm{l}$ (plasma) and $1.0-100 \mathrm{pmol}$ (tissues). Only calibration curves with a linearity of the slope $>0.990$ were considered acceptable. The limit of detection was $0.05 \mu \mathrm{mol} / \mathrm{l}$ (plasma) and 1 pmol (tissues), and the lower limit of quantification was $0.1 \mu \mathrm{mol} / \mathrm{l}$ (plasma) and $1.3 \mathrm{pmol}$ (tissues). Areas under the curve were calculated from the plots of mean concentration versus time using the trapezoidal rule.

\section{Statistics}

Antitumor activity and differences in the exposure of tissues to platinum were evaluated by Student's $t$-test.

\section{Results \\ Antitumor activity of cisplatin nanocapsules}

The in-vivo antitumor efficacy of cisplatin nanocapsules was tested in mice bearing OVCAR-3 xenografts, of which the sensitivity to cisplatin is well established [24]. Cisplatin in solution and the cisplatin nanocapsules were injected twice with a 1-week interval up to $5 \mathrm{mg}$ cisplatin/ $\mathrm{kg}$, corresponding to the MTD for cisplatin [26]. The weight loss caused by cisplatin nanocapsules at $3 \mathrm{mg} / \mathrm{kg}$ was slightly, but not significantly, stronger than that induced by the corresponding dose of free drug $(P=0.1)$ (Table 1). Fourteen days after first treatment with the doses tested, the loss of weight was fully reversed. Higher doses of cisplatin nanocapsules up to $5 \mathrm{mg} / \mathrm{kg}$ led to a reversible weight loss up to $25 \%$ within 2 weeks of treatment (data not shown), and were therefore considered too toxic. As a consequence, the antitumor activity was compared up to a dose of $3 \mathrm{mg} / \mathrm{kg}$ for both formulations.

Treatment with $1.5 \mathrm{mg} / \mathrm{kg}$ cisplatin delayed xenograft growth by 18 days (Table 1 ). A dose of $3 \mathrm{mg} / \mathrm{kg}$ cisplatin induced regression of the tumors to $30 \%$ of the initial tumor volume after 20 days, after which the tumors resumed growth. Cisplatin administered in nanocapsules delayed tumor growth and induced regression, albeit slightly less effectively than the corresponding doses of

Table 1 Activity of cisplatin nanocapsules compared with cisplatin in nude mice bearing OVCAR-3 xenografts

\begin{tabular}{|c|c|c|c|c|}
\hline $\begin{array}{l}\text { Treatment weekly x2 } \\
\text { (mg cisplatin } / \mathrm{kg} \text { ) }\end{array}$ & $\begin{array}{l}\text { Maximum weight } \\
\text { loss } \pm \text { SD (\%) (day) }\end{array}$ & $\begin{array}{l}\text { Weight day } \\
14 \pm \text { SD (\%) }\end{array}$ & $\begin{array}{l}\text { Toxic } \\
\text { deaths }\end{array}$ & $\begin{array}{c}\text { Optimum T/C } \\
(\%)^{\mathrm{a}, \mathrm{b}} \text { (day) (tumors) }\end{array}$ \\
\hline \multicolumn{5}{|l|}{ Cisplatin } \\
\hline 1.5 & 0 & $105.4 \pm 2.4$ & $0 / 5$ & $26 * *(18)(7)$ \\
\hline 3 & $4 \pm 5.5(10)$ & $103.4 \pm 1.9$ & $0 / 5$ & $8 * * *$ (20) (8) \\
\hline \multicolumn{5}{|l|}{ Nanocapsules } \\
\hline 1.5 & $3.4 \pm 13.5(7)$ & $103.7 \pm 9.1$ & $0 / 5$ & $65 *(5)(8)$ \\
\hline 3 & $9.0 \pm 2.5(10)$ & $99.5 \pm 3.2$ & $0 / 5$ & $12 * * *(20)(9)$ \\
\hline
\end{tabular}

${ }^{a} \mathrm{~T} / \mathrm{C}(\%)$, optimal value of the mean of relative tumor volume in treated group/mean of relative tumor volume in control group $\times 100$, calculated within 5 weeks after completing chemotherapy.

bSignificant differences, ${ }^{*} P<0.05 ;{ }^{*} P<0.01$ and $* * * P<0.001$, between treated and control animals evaluated by Student's $t$-test. 
the free drug. At $1.5 \mathrm{mg} / \mathrm{kg}$ cisplatin nanocapsules, tumor growth was delayed by 14 days, whereas at $3 \mathrm{mg} / \mathrm{kg}$ the tumor volume was reduced to $41 \%$ of the initial volume on day 20 after the first injection. The difference in antitumor activity between cisplatin nanocapsules and the free drug at $3 \mathrm{mg} / \mathrm{kg}$ was not significant $(P=0.23$; Table 1).

Biodistribution of platinum from cisplatin nanocapsules To gain insight into the fate of the cisplatin nanocapsules after i.v. administration, the platinum concentrations in plasma and several tissues were determined at different time-points up to $24 \mathrm{~h}$ after a single i.v. injection of cisplatin and cisplatin nanocapsules at a dose of $4 \mathrm{mg}$ cisplatin/kg (Fig. 1). As it concerned a single dose, it was chosen above the MTD of cisplatin nanocapsules to facilitate detection. The free drug was rapidly cleared from circulation by the kidney, the excretory organ of cisplatin that showed higher platinum contents than tumor, liver, lungs, and spleen at all time-points, in agreement with previous studies [7,15,16]. Administration of cisplatin nanocapsules did neither prolong the circulation time of cisplatin, nor did it enhance the accumulation of platinum in the tumor, compared with administration of cisplatin in solution (Fig. 1, panels a and $b)$. The data suggest that during the first hour after injection, removal of platinum from nanocapsules from the blood stream by the kidneys was slightly less than that of the free drug (Fig. 1c). In contrast, already $20 \mathrm{~min}$ after injection, cisplatin from nanocapsules showed strong

Fig. 1
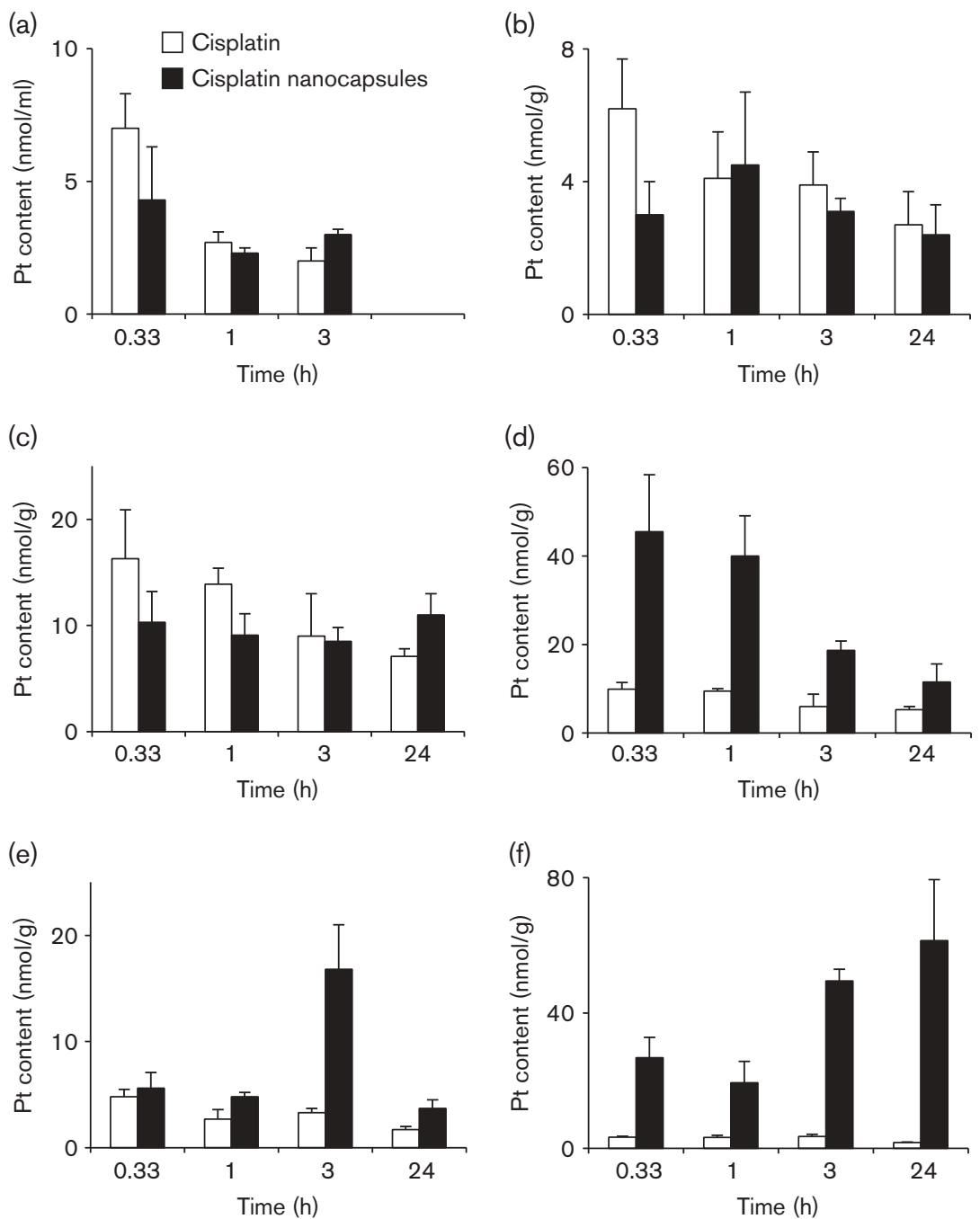

Pharmacokinetic profile of platinum (Pt) in plasma (a), tumor (b), kidney (c), liver (d), lung (e), and spleen (f) of nude mice bearing OVCAR-3 tumors, following a single intravenous dose of cisplatin or cisplatin nanocapsules corresponding to $4 \mathrm{mg}$ cisplatin/ $\mathrm{kg}$. The Pt content in plasma at $24 \mathrm{~h}$ was not determined. Values are expressed as mean $\pm S D(n=3)$. 
Table 2 Exposure of different tissues to platinum after administration of cisplatin at $4 \mathrm{mg} / \mathrm{kg}$ in solution or in nanocapsules to nude mice bearing OVCAR-3 xenografts

\begin{tabular}{lcc}
\hline Tissue & Cisplatin $^{\mathrm{a}}$ & Cisplatin nanocapsules $^{\mathrm{a}}$ \\
\hline Plasma $^{\mathrm{b}}$ & $0.5 \pm 0.1$ & $0.5 \pm 0.1$ \\
Tumor $_{\text {Kidney }}$ & $5.0 \pm 0.9$ & $4.0 \pm 0.5$ \\
Liver & $12.1 \pm 3.0$ & $13.8 \pm 2.3$ \\
Lung & $8.4 \pm 2.0$ & $24.0 \pm 4.0^{\mathrm{c}}$ \\
Spleen & $3.6 \pm 0.5$ & $12.4 \pm 1.1^{\mathrm{c}}$ \\
\hline
\end{tabular}

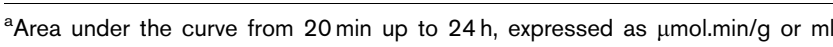
(mean $\pm \mathrm{SD}, n=3$ )

betermined up to $t=3 \mathrm{~h}$.

${ }^{\mathrm{c}}$ Higher exposure to platinum $(P<0.01)$ from nanocapsules than from solution.

accumulation in the liver, with a platinum level 4.5 -fold higher than that in cisplatin-treated mice (Fig. 1d). At later time-points peak levels of platinum from cisplatin nanocapsules were measured in the lung at $3 \mathrm{~h}$ (Fig. 1e), and in the spleen (Fig. 1f) in which the platinum content increased up to $24 \mathrm{~h}$ after injection. The exposure of the liver, lung, and spleen to cisplatin as measured by the areas under the curve was increased 3-fold, 3.5-fold, and 20-fold, respectively, with the nanocapsule formulation as compared with treatment with cisplatin in solution (Table 2).

\section{Discussion}

Cisplatin nanocapsules present a new lipid formulation of the anticancer drug cisplatin, in which an essentially water-free nanoprecipitate of the drug is covered by a single lipid bilayer $[17,18]$. This study reports the first in-vivo results obtained with cisplatin nanocapsules. The therapeutic effectiveness and the biodistribution of cisplatin nanocapsules were compared with those of cisplatin in solution in nude mice bearing human ovarian carcinoma OVCAR-3 xenografts.

At the doses tested, cisplatin nanocapsules and the free drug exhibited similar antitumor efficacies, consistent with the similar levels of accumulation of platinum in the tumor obtained with the two formulations. As the lifetime of cisplatin nanocapsules in mouse serum in vitro

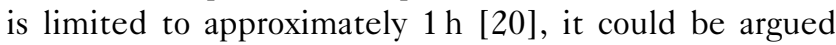
that the similarity in antitumor efficacy and accumulation in the tumor of the two formulations is owing to an immediate and complete release of content of the nanocapsules upon i.v. administration. However, the different biodistribution patterns of platinum from the two formulations indicate otherwise. Whereas the kidneys cleared the free drug from circulation, platinum from cisplatin nanocapsules rapidly accumulated in the liver, and more gradually in the lung and the spleen, indicating that at least part of the nanocapsules remained in circulation beyond $3 \mathrm{~h}$ after injection. The results imply that part of the inhibition of tumor growth observed upon administering cisplatin nanocapsules must originate from nanocapsules accumulating in the tumor, and, as a consequence, that once in the tumor, the nanocapsules release cisplatin to exert their cytotoxic effect. We conclude that cisplatin nanocapsules are effective in inhibiting tumor growth.

The antitumor efficacy of the cisplatin nanocapsules in vivo reported here does not correlate with the in-vitro data, which demonstrated a strong increase in cytotoxicity of cisplatin nanocapsules compared with the free drug [17]. Possible explanations include differences in stability of the nanocapsules in tissue culture medium and in plasma, differences in cell accessibility between cells cultured in vitro and cells in a tumor, and differences in the mechanism of cellular drug uptake. Whereas the uptake of free cisplatin released from the nanocapsules in the interstitial space is likely to predominate in the tumor [27], endocytosis of intact nanocapsules accounts for the increased cytotoxicity in vitro (our unpublished results).

The biodistribution of cisplatin nanocapsules appeared to be different from that of SPI-077, a PEGylated liposomal formulation of cisplatin, in tumor-bearing mice $[7,15,16]$. SPI-077 liposomes exhibit a prolonged circulation time compared with the free drug, and increased accumulation in the tumor. Furthermore, the relative rate of accumulation of platinum from SPI-077 in the liver and spleen is slower and the extent of accumulation relative to that of the free drug is less compared with platinum from cisplatin nanocapsules. A number of factors are likely to account for the different biodistribution patterns of platinum from nanocapsules and from SPI-077. First, contrary to cisplatin nanocapsules, SPI-077 liposomes hardly release contents in plasma $[7,16,19]$. Next, unlike SPI-077, cisplatin nanocapsules have a negative surface charge originating from the anionic phospholipid PS that cannot be completely shielded by PEGylation [20], and is known to enhance removal from circulation by the reticulo-endothelial system [21], and by the liver in particular [28]. Particle size is another important parameter determining the rate of clearance from circulation. Whereas SPI-077 liposomes have an average particle size of $110 \mathrm{~nm}$ and a narrow size distribution [7], preparations of nanocapsules are more heterogeneous and contain larger particles $[17,19,20]$ that are more prone to clearance [29]. Furthermore, the different physical properties of the particles, that is, the solid core of the nanocapsules versus the aqueous interior of the liposomes, may influence pharmacokinetics. Finally, the rate of clearance depends on the amount of lipid given. The amount of lipid administered with SPI-077 is at least two orders of magnitude higher than the amount of lipid contained in a corresponding dose of cisplatin nanocapsules owing to the huge difference in drug-to-lipid ratios between the formulations $(c f .[7,19])$. As a consequence, the doses of SPI-077 generally used are expected to saturate the mechanism(s) of clearance, in contrast to what can be expected for the corresponding doses of 
cisplatin nanocapsules [21,30,31], providing an additional explanation for the different rates of clearance.

The differences in pharmacological behavior between SPI-077 and our formulation suggest that the accumulation of cisplatin in the tumor and the antitumor efficacy could be improved by increasing nanocapsule stability in plasma, and by preventing the rapid scavenging by the liver and spleen. The latter may be accomplished by reducing the negative surface charge and/or the particle size of the cisplatin nanocapsules, or by saturating the mechanism(s) of clearing by administering liposomes before the nanocapsules.

The importance of the particles' surface charge in determining the biodistribution is further suggested by comparison of our results with those recently reported for cisplatin-loaded hydrophobically modified glycol chitosan nanoparticles [32]. These particles carry a positive surface charge, and with a mean diameter of $300-500 \mathrm{~nm}$, they are larger than our cisplatin nanocapsules. Upon i.v. administration in tumor-bearing mice, the cisplatinloaded hydrophobically modified glycol chitosan nanoparticles did not end up in the liver and the spleen, but accumulated in the tumor, exhibiting reduced toxicity and improved antitumor efficacy compared with free cisplatin [32].

Alternatively, cisplatin nanocapsules could be useful for applications such as sustained drug release after intraperitoneal administration for treatment of peritoneal deposits, or infusion into the hepatic artery in case of liver metastases. Previously, favorable anticancer activities were reported for intraperitoneally administered, cisplatin-releasing, polymer-based microspheres [33] and nanoparticles [34].

Interestingly, the application of the nanocapsule technology to the cisplatin-derived anticancer drug carboplatin recently yielded a formulation with a drug-to-lipid ratio that is 15 -fold lower than that of cisplatin nanocapsules [35]. Carboplatin nanocapsules can be sized by extrusion and prepared with lower PS contents, rendering such a formulation promising for in-vivo application.

\section{Acknowledgements}

We appreciate the technical assistance provided by Kees Smid.

This research was supported by the Dutch Cancer Society (KWF Kankerbestrijding) and by NanoNed, a national nanotechnology program coordinated by the Dutch Ministry of Economic Affairs.

\section{References}

1 Wang D, Lippard SJ. Cellular processing of platinum anticancer drugs. Nat Rev Drug Discov 2005; 4:307-320.
2 Akaboshi M, Kawai K, Maki H, Akuta K, Ujeno Y, Miyahara T. The number of platinum atoms binding to DNA, RNA and protein molecules of HeLa cells treated with cisplatin at its mean lethal concentration. Jpn J Cancer Res 1992; 83:522-526.

3 Gonzalez VM, Fuertes MA, Alonso C, Perez JM. Is cisplatin-induced cell death always produced by apoptosis? Mol Pharmacol 2001; 59:657-663.

4 Cvitkovic E. Cumulative toxicities from cisplatin therapy and current cytoprotective measures. Cancer Treat Rev 1998; 24:265-281.

5 Reedijk J. Why does cisplatin reach guanine-n7 with competing s-donor ligands available in the cell? Chem Rev 1999; 99:2499-2510.

6 Giaccone G. Clinical perspectives on platinum resistance. Drugs 2000; 59 (Suppl 4):9-17.

7 Newman MS, Colbern GT, Working PK, Engbers C, Amantea MA Comparative pharmacokinetics, tissue distribution, and therapeutic effectiveness of cisplatin encapsulated in long-circulating, pegylated liposomes (SPI-077) in tumor-bearing mice. Cancer Chemother Pharmacol 1999; 43:1-7.

8 Boulikas T. Low toxicity and anticancer activity of a novel liposomal cisplatin (lipoplatin) in mouse xenografts. Oncol Rep 2004; 12:3-12.

9 Vaage J, Donovan D, Wipff E, Abra R, Colbern G, Uster P, et al. Therapy of a xenografted human colonic carcinoma using cisplatin or doxorubicin encapsulated in long-circulating pegylated stealth liposomes. Int J Cancer 1999; 80:134-137.

10 Veal GJ, Griffin MJ, Price E, Parry A, Dick GS, Little MA, et al. A phase I study in paediatric patients to evaluate the safety and pharmacokinetics of SPI-77, a liposome encapsulated formulation of cisplatin. Br J Cancer 2001 84:1029-1035.

11 Harrington KJ, Lewanski CR, Northcote AD, Whittaker J, Wellbank $H_{\text {, }}$ Vile RG, et al. Phase I-II study of pegylated liposomal cisplatin (SPI-077) in patients with inoperable head and neck cancer. Ann Oncol 2001; 12: 493-496.

12 Boulikas T, Stathopoulos GP, Volakakis N, Vougiouka M. Systemic lipoplatin infusion results in preferential tumor uptake in human studies. Anticancer Res 2005; 25:3031-3039.

13 Wittgen BP, Kunst PW, van der Born K, van Wijk AW, Perkins W, Pilkiewicz FG, et al. Phase I study of aerosolized SLIT cisplatin in the treatment of patients with carcinoma of the lung. Clin Cancer Res 2007; 13:2414-2421.

14 Meerum Terwogt JM, Groenewegen G, Pluim D, Maliepaard M, Tibben MM, Huisman A, et al. Phase I and pharmacokinetic study of SPI-77, a liposomal encapsulated dosage form of cisplatin. Cancer Chemother Pharmacol 2002; 49:201-210.

15 Zamboni WC, Gervais AC, Egorin MJ, Schellens JH, Zuhowski EG, Pluim D et al. Systemic and tumor disposition of platinum after administration of cisplatin or STEALTH liposomal-cisplatin formulations (SPI-077 and SPI-077 $\mathrm{B} 103)$ in a preclinical tumor model of melanoma. Cancer Chemother Pharmacol 2004; 53:329-336.

16 Bandak S, Goren D, Horowitz A, Tzemach D, Gabizon A. Pharmacological studies of cisplatin encapsulated in long-circulating liposomes in mouse tumor models. Anticancer Drugs 1999; 10:911-920.

17 Burger KN, Staffhorst RW, de Vijlder HC, Velinova MJ, Bomans PH, Frederik PM, et al. Nanocapsules: lipid-coated aggregates of cisplatin with high cytotoxicity. Nat Med 2002; 8:81-84.

18 Chupin V, de Kroon Al, de Kruijff B. Molecular architecture of nanocapsules, bilayer-enclosed solid particles of cisplatin. J Am Chem Soc 2004; 126:13816-13821.

19 de Kroon Al, Staffhorst RW, de Kruijff B, Burger KN. Cisplatin nanocapsules. Methods Enzymol 2005; 391:118-125.

20 Velinova MJ, Staffhorst RW, Mulder WJ, Dries AS, Jansen BA, de Kruijff B, et al. Preparation and stability of lipid-coated nanocapsules of cisplatin: anionic phospholipid specificity. Biochim Biophys Acta 2004; 1663: 135-142.

21 Woodle MC, Lasic DD. Sterically stabilized liposomes. Biochim Biophys Acta 1992; 1113:171-199.

22 Burger KN, Staffhorst RW, de Kruijff B. Interaction of the anti-cancer drug cisplatin with phosphatidylserine in intact and semi-intact cells. Biochim Biophys Acta 1999; 1419:43-54.

23 Workman P, Twentyman P, Balkwill F, Balmain A, Chaplin D, Double J, et al. United Kingdom Co-Ordinating Committee on Cancer Research (UKCCCR) Guidelines for the Welfare of Animals in Experimental Neoplasia (Second Edition). Br J Cancer 1998; 77:1-10.

24 Treskes M, Boven E, Holwerda U, Pinedo HM, van der Vijgh WJ. Time dependence of the selective modulation of cisplatin-induced nephrotoxicity by WR2721 in the mouse. Cancer Res 1992; 52:2257-2260.

25 Van Moorsel CJ, Pinedo HM, Smid K, Comijn EM, Voorn DA, Veerman G, et al. Schedule dependent pharmacodynamic effects of gemcitabine and 
cisplatin in mice bearing Lewis Lung murine non-small cell lung tumors. Eur J Cancer 2000; 36:2420-2429.

26 Kolfschoten GM, Pinedo HM, Scheffer PG, Schluper HM, Erkelens CA, Boven E. Development of a panel of 15 human ovarian cancer xenografts for drug screening and determination of the role of the glutathione detoxification system. Gynecol Oncol 2000; 76:362-368.

27 Drummond DC, Meyer O, Hong K, Kirpotin DB, Papahadjopoulos D. Optimizing liposomes for delivery of chemotherapeutic agents to solid tumors. Pharmacol Rev 1999; 51:691-743.

28 Scherphof GL, Kamps JA. The role of hepatocytes in the clearance of liposomes from the blood circulation. Prog Lipid Res 2001; 40:149-166.

29 Liu D, Mori A, Huang L. Role of liposome size and RES blockade in controlling biodistribution and tumor uptake of GM1-containing liposomes. Biochim Biophys Acta 1992; 1104:95-101.

30 Senior J, Crawley JC, Gregoriadis G. Tissue distribution of liposomes exhibiting long half-lives in the circulation after intravenous injection. Biochim Biophys Acta 1985; 839:1-8.
31 Allen TM, Hansen C. Pharmacokinetics of stealth versus conventional liposomes: effect of dose. Biochim Biophys Acta 1991; 1068: 133-141.

32 Kim J-H, Kim Y-S, Park K, Lee S, Nam HY, Min KH, et al. Antitumor efficacy of cisplatin-loaded glycol chitosan nanoparticles in tumor-bearing mice. J Control Release 2008; 127:41-49.

33 Tokuda K, Natsugoe S, Shimada M, Kumanohoso T, Baba M, Takao S, et al. Design and testing of a new cisplatin form using a base material by combining poly-D,L-lactic acid and polyethylene glycol acid against peritoneal metastasis. Int J Cancer 1998; 76:709-712.

34 Xu P, Van Kirk EA, Murdoch WJ, Zhan Y, Isaak DD, Radosz M, et al. Anticancer efficacies of cisplatin-releasing $\mathrm{pH}$-responsive nanoparticles. Biomacromolecules 2006; 7:829-835.

35 Hamelers IH, van Loenen E, Staffhorst RW, de Kruijff B, de Kroon Al. Carboplatin nanocapsules: a highly cytotoxic, phospholipidbased formulation of carboplatin. Mol Cancer Ther 2006; 5:2007-2012. 